\title{
Void Swelling in Self-Ion Irradiated Ferritic-Martensitic Alloy T91
}

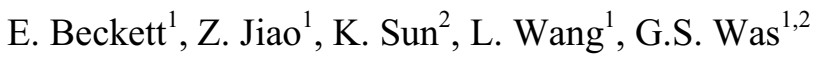 \\ 1. Department of Nuclear Engineering and Radiological Sciences, University of Michigan, Ann Arbor, MI 48109 \\ 2. Department of Materials Science and Engineering, University of Michigan, Ann Arbor, MI 48109
}

Determining the microstructural behavior of body centered cubic (BCC) ferritic-martensitic alloys is important for predicting the safety and structural integrity of fast spectrum reactors. Of particular interest is the phenomenon of radiation-induced void swelling, which could potentially cause dimensional changes in key structural components in reactors. Irradiations performed with heavy ion irradiations can be used to model neutron irradiations with the benefits of accelerated dose rate, decreased irradiation time required and excellent temperature control of irradiated samples.

Self-ion irradiation experiments have been performed on ferritic-martensitic alloy T91 to determine swelling behavior at $440^{\circ} \mathrm{C}$ to doses of $280 \mathrm{dpa}$ and $375 \mathrm{dpa}$, in order to examine the effect of irradiation dose on void size, density and swelling. T91 is a modified 9Cr-1Mo alloy, which has demonstrated swelling resistance in previous neutron irradiation studies.[1] Samples were preimplanted with $100 \pm 10$ atom parts per million (appm) helium at a depth of 300-1000 $\mathrm{nm}$ from the sample surface. Irradiations were performed with $5 \mathrm{MeV} \mathrm{Fe}++$ ions on samples using raster scanning on a Tandetron accelerator at the Michigan Ion Beam Laboratory. The effect of dose on void swelling was determined by examining the void distribution using transmission electron microscopy (TEM). TEM samples were prepared using the liftout technique on a FEI Quanta Focused Ion Beam (FIB) system.

The irradiated microstructure at $280 \mathrm{dpa}$ is shown in Figure 2. The microstructure includes many dislocation loops, lines and precipitates, which is characteristic of ferritic-martensitic alloys. The damage curve and the pre-implanted helium distribution were superimposed over the sample irradiated to 375 dpa as shown in Figure 1. A comparison of void data at both doses is given in Table 1. Voids preferentially nucleated over the area pre-implanted with helium. The additional $100 \mathrm{dpa}$ of dose greatly increased void diameter, density and swelling, which indicates that the sample is still in the nucleating regime at $280 \mathrm{dpa}$ but is entering the steady state growth regime by $375 \mathrm{dpa}$. Despite the large increase in void number, density and swelling at $375 \mathrm{dpa}$, T91 demonstrates superior swelling resistance to high doses, relative to stainless steel alloys which reach swelling rates as high as $1 \% / \mathrm{dpa}$. [2] Though the amount of neutron data is limited, T91 irradiated in the Fast Flux Test Facility at $420^{\circ} \mathrm{C}$ to 203 dpa showed swelling of $1.76 \%$. [1] This, when compared to the self-ion irradiated data, indicates that self-ion irradiations may include a longer nucleation regime before entering the growth regime. The swelling-dose curve is plotted in Figure 3 and the steady state swelling rate was calculated to be $0.003 \%$ /dpa based upon these two conditions. This is similar to the swelling rate of $0.002 \%$ calculated by Sencer et al. in a neutron irradiation of HT9, another ferritic-martensitic alloy, up to 155 dpa at $443^{\circ} \mathrm{C}$.[3]

Further work will include irradiations to higher doses to map out the steady state swelling rate, as well as examining the effect of temperature on void nucleation and growth behavior. Additionally, other alloys including various heats and heat treatments of HT9, will be irradiated and examined, in order to determine an accurate method for modeling neutron damage with heavy ions.

References:

[1] D. Gelles, Journal of Nuclear Materials 237 (1996) 293-298. 
[2] F. Garner, M.B. Toloczko, B.H. Sencer, Journal of Nuclear Materials 276 (2000) 123-142.

[3] B.H. Sencer, J.R. Kennedy, J.I. Cole, S.A Maloy, F.A Garner, Journal of Nuclear Materials 393 (2009) 235-241.

[4] This work was supported by TerraPower, LLC and in part by NSF grant \#DMR-9871177.

Table 1. Comparison of void diameter, density and swelling in samples irradiated to 280 dpa and $375 \mathrm{dpa}$ at $480^{\circ} \mathrm{C}$ at a dose rate of $7.92 \times 10^{-4}$ and $5.4 \times 10^{-4} \mathrm{dpa} / \mathrm{s}$, respectively.

\begin{tabular}{|l|l|l|l|l|l|l|l|}
\hline Alloy & $\begin{array}{l}\text { Temperature } \\
\left({ }^{\circ} \mathbf{C}\right)\end{array}$ & $\begin{array}{l}\text { Dose } \\
(\mathbf{d p a})\end{array}$ & $\begin{array}{l}\text { He Implanted } \\
(\mathbf{a p p m})\end{array}$ & $\begin{array}{l}\text { \# of Voids } \\
\text { Void Density } \\
\left(\mathbf{m}^{-3}\right)\end{array}$ & $\begin{array}{l}\text { Average } \\
\text { Diameter }(\mathbf{n m})\end{array}$ & $\begin{array}{l}\text { Swelling } \\
(\mathbf{\%})\end{array}$ \\
\hline T91 & 440 & 280 & 100 & 529 & $2.82 \times 10^{20}$ & 9.44 & $0.023 \%$ \\
\hline T91 & 440 & 375 & 100 & 785 & $8.85 \times 10^{20}$ & 12.5 & 0.33 \\
\hline
\end{tabular}

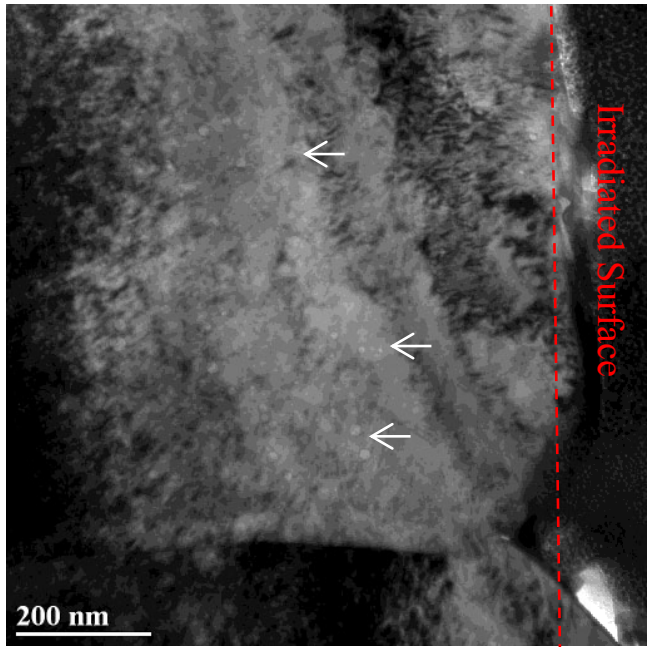

Figure 2. T91 irradiated to $280 \mathrm{dpa}$ at $440^{\circ} \mathrm{C}$ and at $7.92 \times 10^{-4} \mathrm{dpa} / \mathrm{s}$. Selected voids marked with white arrows.

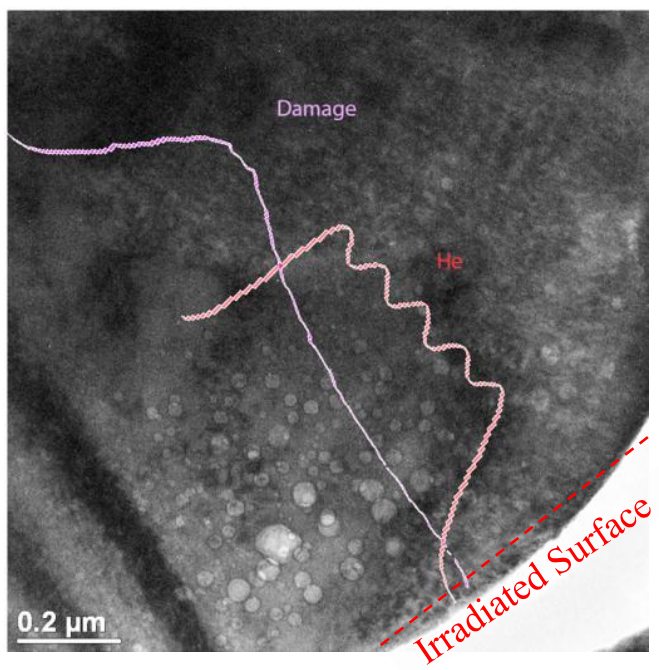

Figure 1. $\mathrm{Fe}^{++}$irradiation damage curve and implanted helium distributed superimposed over sample irradiated to $375 \mathrm{dpa}$ at $480^{\circ} \mathrm{C}$ with a dose rate of $5.4 \times 10^{-4} \mathrm{dpa} / \mathrm{s}$.

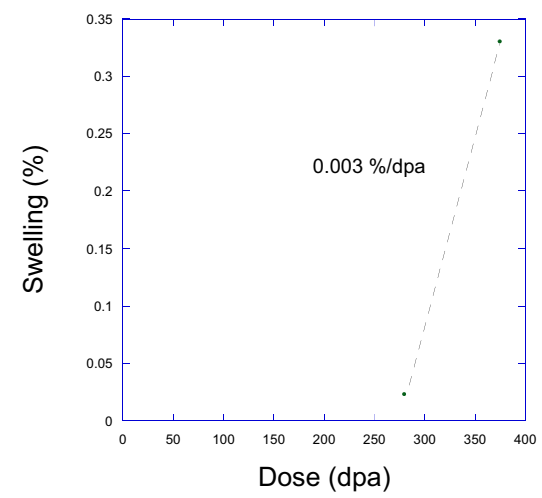

Figure 3. Swelling versus dose in irradiated $\mathrm{T} 91$ at $440^{\circ} \mathrm{C}$ 